\title{
NATHANAEL WEST Y LA ÉTICA DE INTERIM
}

\section{Juan Manuel Castro Carracedo}

Universidad de Salamanca

\begin{abstract}
RESUMEN: La última novela de Nathanael West, The Day of the Locust, ha sido tachada de inmoral o poco ética por la crítica debido al aparente rechazo que sus personajes hacen de los principios tradicionales. Sin embargo, considerada desde una perspectiva escatológica, esta conducta responde a un sistema ético prácticamente desconocido fuera del ámbito teológico pero de larga raigambre en la cultura occidental: la ética de interim. Este comportamiento, propio de sociedades con expectativas apocalípticas, minimiza el valor de la moral personal y el deber cívico por confiar en una catástrofe global inminente. El resultado es un estado de suspensión ética, fácilmente confundible con la amoralidad, donde los compromisos cotidianos se eliminan y los sentimientos se trivializan hasta suprimirse en su totalidad. Este estudio analiza los factores sociales y psicológicos que conforman el código ético de The Day of the Locust para demostrar que están motivados por una percepción catastrofista del tiempo que redefine las actitudes de los protagonistas y los exime de sus responsabilidades vitales. De este modo se explica cómo West recupera y actualiza el concepto de ética de interim para que refleje la ansiedad existencial de la vida moderna.
\end{abstract}

ABSTRACT: Nathanael West's last novel The Day of the Locust has often been labelled as immoral or unethical by modern scholars, due to the characters' apparent rejection of traditional principles and respectable ideologies. However, when considered from the eschatological perspective, this kind of conduct clearly responds to an ethical system, fairly unknown outside theological circles, but with a long tradition in Western culture: the "interim ethics". This behaviour, commonly rooted in societies with apocalyptic expectations, belittles the value of personal morality and civic duty, supported by a firm belief in an imminent global catastrophe. The result is a state of ethical suspension, easily confused with amorality, where ordinary responsibilities are cancelled and common feelings are trivialized or even completely suppressed. This paper analyses the social and psychological factors that shape the ethical code presented in The Day of the Locust in order to demonstrate that they are motivated by a disastrous perception of time which redefines the attitudes of the protagonists and relieves them of their vital exigencies. Thus, it will be explained how West recovers and renews the concept of "interim ethics" so that it reflects the existential anxiety of modern life. 
PALABRAS CLAVE: Nathanael West, The Day of the Locust, ética de interim, literatura apocalíptica.

KEYWORDS: Nathanael West, The Day of the Locust, interim ethics, apocalyptic literature.

\section{Introducción}

Cuando en 1938 Nathanael West decidió cambiar el título de su novela The Cheated por el definitivo The Day of the Locust ${ }^{1}$, argumentando que era demasiado pretencioso ${ }^{2}$, el neoyorkino estaba haciendo, probablemente de forma inconsciente, un gran acierto: el título The Cheated contiene de forma implícita dos afirmaciones que no pueden encontrarse en esta obra: alguien que engañe y un paradigma de valores según el cual se esté engañando. $D L$ no muestra ni lo uno ni lo otro.

Dentro de la reducida obra de Nathanael West, $D L$ está considerada como su novela más ambiciosa y con mayores expectativas, aunque éstas nunca llegaron a materializarse de forma completa. Frente a la redondez y precisión de Miss Lonelyhearts, $D L$ carece de la intensidad característica en West precisamente por sus altas pretensiones iniciales. Aunque son varias las razones por las que la novela fue, en palabras de su autor, "a definite flop", parece haber un denominador común entre los defectos que la crítica ha destacado en la obra: su aparente falta de moralidad. Victor Comerchero, por ejemplo, afirmaba:

It differs from the other [West's] novels by failing to focus indignation upon any single aspect of existence. [...] For present purposes, it is not important that one agree with the author's central statement; what is important is that one is able to formulate it. In The Day of the Locust, one finds it difficult to crystallize in one's mind the central point of the novel. In many respects, the reader's inability to do so compromises the major failing of the novel. (1964: 120)

1. En adelante, $D L$. Todas las citas de este y otros escritos de Nathanael West remitirán a la edición de Sacvan Bercovitch (1997) e incluirán el número de página en dicha edición.

2. "How about the title? Do you like 'The Cheated'? I have started to wonder if it wasn't a little too pretentious, like most of the Nineteenth Century 'The....' titles." (“Letter to Bennett Cerf', June 7, 1938; p. 785).

3. "The book is what the publisher, at least, calls a definite flop. It will hardly reach a sale of 1400 copies." ("Letter to Edmund Wilson", June 30, 1939; p. 796). 
En el mismo sentido, Stanley Hyman opinaba lo siguiente:

Despite this [the riot scene] and other very powerful scenes, I think that The Day of the Locust ultimately fails as a novel. Shifting from Tod to Homer and back to Tod, it has no dramatic unity, and in comparison with Miss Lonelyhearts, it has no moral core. (1962: 34)

La falta de un núcleo ético, lo que Florence Britton condensó en la frase "The Day of the Locust is emotionally inert" (1939: 7), ha sido una crítica constante entre los estudios westianos. Sin embargo, atendiendo al aspecto finalista de la obra, observamos que esa falta de moralidad no es más que aparente y que las actitudes éticas expresadas en la novela responden en realidad a un sistema de valores concreto. Este sistema, que recibe el nombre específico de "ética de interim", y su repercusión en $D L$, suponen el objeto final de este estudio.

\section{La ética de Interim}

Pese a ser prácticamente desconocido fuera del ámbito de los estudios neotestamentarios, el término "ética de interim" cuenta con una larga historia de más de cien años a su espalda. Su creador, Albert Schweitzer, lo empleó por primera vez en su polémico estudio The Quest of the Historical Jesus para referirse a la peculiar ética "de emergencia" que Cristo predicó ante sus discípulos anticipando la inminencia del cataclismo apocalíptico:

And this, therefore, is the only message which He commits to His disciples when sending them forth. What this repentance, supplementary to the law, the special ethic of the interval before the coming of the Kingdom (Interimesethik) is, in its positive acceptation, He explains in the Sermon on the Mount. (Schweitzer 1910: $354)^{4}$

Según Schweitzer y sus seguidores de la Thoroughgoing Eschatology, las doctrinas de Jesucristo, compendiadas parcialmente en el Sermón de la Montaña (Mt. 5:1-7:29, Lc. 6:20-49), estarían mediatizadas por sus creencias escatológicas. Su firme convencimiento en la cercanía del fin del mundo le haría promulgar

4. En realidad, aunque el creador del término "ética de interim" es Schweitzer, el concepto no era completamente nuevo. La necesidad de interpretar las enseñanzas de Jesucristo bajo el prisma de la escatología fue planteada por primera vez por Johannes Weiss en Die Predigt Jesu vom Reiche Gottes (La proclamación de Jesús del Reino de Dios) en 1892. En este ensayo, el teólogo alemán adelantó la mayoría de los principios de la que sería posteriormente la Interimsethik de Schweitzer. 
una serie de postulados idealistas, imposibles de llevar a la práctica, entre los que se encontrarían el perdón absoluto de los agravios, el amor incondicional a los enemigos, el pacifismo ante las agresiones ajenas, etc. Aspectos fundamentales en aquel momento, tales como la estrategia política ante Roma o las discrepancias entre sectas judaicas, serían irrelevantes para Jesucristo ante la inminencia del fin (Mt. 24-25) y, por ello, no se pronunció sobre ello en ningún momento de los Evangelios (Knox 1958: 62). A esta doctrina, que más que una moral completa debería entenderse como un conjunto diseminado de modelos carismáticos de conducta, la denomina Schweitzer ética de interim debido a su inevitable limitación temporal.

La teología de principios del siglo XX, sin embargo, no estaba tan dispuesta a aceptar la teoría de que Cristo hubiera enseñado una "ética de los últimos días", especialmente por lo que implicaba en relación con el pensamiento apocalíptico: pensadores como Karl Barth o Amos Wilder rebajaron el contenido escatológico de las enseñanzas de Jesucristo y buscaron propuestas alternativas a la hipótesis de Schweitzer. Durante los años 30s, el concepto de ética de interim quedaba escindido de la figura de Cristo, aunque no se desterraba por completo: una nueva acepción, basada en las enseñanzas de San Pablo, acabó imponiéndose ${ }^{5}$.

Tras la muerte de Cristo, y ante el retraso de la Segunda Venida, San Pablo dotó de actualidad pragmática las directrices predicadas por Cristo. Su doctrina servía de respuesta a las muchas cuestiones que el aplazamiento de la Parusía levantaba entre las primeras comunidades cristianas, pero sin renunciar al carácter transitorio que la inminencia escatológica exigía. Frente al desentendimiento completo de los aspectos cotidianos por parte de Cristo, Pablo sí tiene una recomendación para sus feligreses:

Por tanto, los que tienen mujer vivan como si no la tuvieran; los que lloran, como si no llorasen; los que se alegran, como si no se alegrasen; los que compran, como si no poseyesen; los que gozan del mundo, como si no disfrutasen; porque este mundo que contemplamos está para acabar. (1Cor 7: 29-31)

El concepto de ética de interim de Pablo, por tanto, afirma que el período de tiempo antes del fin del mundo es tan breve que las instituciones mundanas y las disposiciones cotidianas (familia, estado, sociedad, etc.) carecen de importancia y cada

5. No veo necesario extenderme aquí sobre la evolución del concepto "ética de interim" durante las primeras décadas del XX. Sobre este tema, pueden consultarse Harkness (1974: cap. 2) y, especialmente, la magnífica bibliografía en Sheenan (1986: 275-87). 
cual puede adaptarlas como crea conveniente o necesario. Pablo destierra el agape y otros idealismos excesivamente utópicos y moldea una ética que, sin sacrificar los principios de Cristo, se corresponde mejor a los tiempos en que vive. Las realidades materiales pierden su significación ante la inminente Parusía y cualquier valor moral es inútil ante la supremacía del Juicio de Cristo en los últimos momentos.

No debe confundirse en ningún momento la ética de interim con el estoicismo clásico. Pese a los orígenes helénicos de Pablo, la ética de interim procede esencialmente de la cultura judía y ya encontramos formulaciones en textos apócrifos anteriores a Jesucristo ${ }^{6}$. La gran divergencia con la filosofía estoica radica en la implicación de los sujetos con las realidades terrenas: frente a la indiferencia conformista del estoicismo, Pablo propone una actitud activa, participativa. Su discurso anima al creyente a gozar, comprar o alegrarse, aunque considerando el carácter relativo que todos estos actos tienen. La ética de interim no defiende la apatheia estoica, sino la relativización de los aspectos terrenales debido a la temporalidad limitada que éstos tienen (Díaz Rodelas 2003: 138-9).

La ética que encontramos en las cartas paulinas, la que quedó fijada como "de interim" en la primera mitad del siglo XX, no es exclusiva de las primeras comunidades cristianas. Un gran número de movimientos apocalípticos, especialmente aquellos que abogaron por el separatismo social, han optado a lo largo de la historia por este posicionamiento ético como patrón de comportamiento. No hace falta retrotraernos a grupos radicales medievales como la secta del "Libre Espíritu" (siglos XIII-XV) o los Taboritas (siglo XV) ${ }^{7}$. En Estados Unidos, y en fechas más próximas, varios grupos han propuesto éticas para intervalos cortos ante la inminencia de la Segunda Venida. Los Shakers, liderados por Ann Lee en el siglo XVIII, defendían el laxismo moral argumentando que no era necesario juzgar en la tierra estando tan cerca el Juicio divino. Por su parte, el movimiento de los Millerite Second Adventists, muy popular en los 1840s, predicaba el desinterés por las cuestiones terrenales, especialmente todo lo concerniente a aspectos políticos y sociales, dado el escaso tiempo que les quedaba. La ética de interim y la interpretación escatológica de la historia humana han ido parejas durante muchos siglos.

6. Aunque hay muestras en el Libro de los Jubileos o en los Oráculos Sibilinos, la obra que mejor expresa este posicionamiento ético es el Libro 4 de Esdrás. Este texto apocalíptico, contemporáneo a las cartas de Pablo, se dirige a una sociedad donde "el que compra como quien va a perderlo, el que comercia como quien no va a recoger fruto, y el que construye como quien no va a habitar la casa, el que siembra como quien no va a recoger la cosecha..." (4Esd 16: 42-45)

7. El mejor estudio sobre estos movimientos, pese a la polémica que lo rodea, sigue siendo The Pursuit of the Millennium de Norman Cohn. 


\section{West y la ética de Interim}

No hay tanta diferencia entre las sociedades de San Pablo, de Ann Lee y de otros grupos que defendían la ética de interim y el Hollywood de $D L$; al fin y al cabo, si hay un calificativo que se ha repetido para referirse al escenario en que ocurren los hechos de $D L$ es "apocalíptico". Sin llegar a la afirmación de Ketterer donde dice que esta obra es el ejemplo más claro de apocalipsis dentro de la ficción norteamericana (1974: 4), multitud de críticos han reparado en la profunda dimensión escatológica de la obra $^{8}$. Pese a la facilidad con la que se utiliza este término dentro de los estudios literarios, $D L$ constituye uno de los pocos casos donde su uso está completamente justificado, como me gustaría mostrar brevemente.

No cabe duda del contenido teleológico que invade $D L$ a todos los niveles, tanto en su estructuración, basada en la crisis continuada y de permanente tendencia hacia el caos, como en su reiterado uso de simbología apocalíptica. Las descripciones de Tod Hackett, narrador y en última instancia "prophet of doom" (p. 309), sobrepasan el pesimismo convencional para alcanzar la retórica escatológica. West responde a la dualidad referencial del discurso apocalíptico al pronosticar paralelamente el fin colectivo de la sociedad-humanidad y el fin particular del individuo. Para el primero, Tod recrea una ciudad de Los Angeles decrépita y autodestructiva, donde las instituciones socioculturales se encaminan irremisiblemente a su desintegración, y los mismos elementos naturales no escapan del decadentismo generalizado. Nada se libra de la atmósfera lúgubre de California porque la amenaza apocalíptica impide cualquier esperanza de mejora futura. Utilizando el símil de la trasera de un estudio de cine, West retrata la sordidez teleológica que su Hollywood ofrece:

This was the final dumping ground. He thought of Janvier's "Sargasso Sea". Just as
the imaginary body of water was a history of civilization in the form of a marine
junkyard, the studio lot was one in the form of a dream dump. A Sargasso of the
imagination! And the dump grew continually, for there wasn't a dream afloat some-
where which wouldn't sooner or later turn up on it, having first made photographic

8. Por hacer un rápido resumen podemos recordar que Zimbaro (1996) lo recoge dentro de su Encyclopedia of Apocalyptic Literature, que John May (1972) lo incluye entre las doce obras características del pensamiento apocalíptico en la novela americana, que Schwartz (1980) y Jones (1989) dedicaron sus tesis a este tema, o que diferentes artículos se centran exclusivamente en este aspecto, como son Alter (1966), Young (1994), Springer (1996), Lewis (1999) o Castro (2005). Hasta cierto punto habría que incluir en este grupo el estudio de Comerchero (1964) ya que considera la novela dentro del género profético, pero en todo momento la describe con las características propias del género apocalíptico. 
by plaster, canvas, lath and paint. Many boats sink and never reach the Sargasso, but no dream ever entirely dissapears. Somewhere it troubles some unfortunate person and some day, when that person has been sufficiently troubled, it will be reproduced on the lot. (p. 326)

Al personalizar esta liminidad en los personajes, Tod es todavía más conclusivo en sus afirmaciones: "At this time Tod knew very little about them except that they had come to California to die" (p. 242). La sociedad hollywoodiense está compuesta por un conjunto de seres que presienten su fin, aceptan su limitación temporal y, por ello, atrofian sus esperanzas y motivaciones. Así, Faye Greener se burla de sus propios sueños, fantaseados sin convicción en delirios de fama y lujo (p. 294) o Homer Simpson acaba lanzándose prácticamente al suicidio en medio de la marabunta humana con que concluye la obra. No existe la posibilidad de ilusión en la gente que rodea a Tod y su cuadro The Burning of Los Angeles (verdadero apocalipsis pictórico, equivalente al último libro de la Biblia) expresa gráficamente ese sentimiento de negatividad completa. La representación de la ciudad y sus habitantes arrasados por las llamas, más que presagiar el final catastrófico al que están abocados, simboliza la realidad finalista en que están sumidos ya: los personajes serán destruidos en el futuro porque son incapaces de concebir esperanzas en el presente 9 .

Para reforzar esta sensación apocalíptica, la obra recurre constantemente a una simbología extraída en su mayor parte del Nuevo Testamento, de modo que el lector no llegue a dudar del mensaje teleológico. Los personajes principales de $D L$ tienen parangón en los protagonistas de los últimos acontecimientos, según la historia bíblica: Tod Hackett es un alter ego del visionario apocalíptico Juan de Patmos, tanto por su función dentro de la estructura de la narración, como por su capacidad noética y su expresión fatalista; Homer Simpson está diseñado siguiento patrones cristológicos, como si se tratase de un Mesías contemporáneo cuyo propósito redentor no se pudiera completar en nuestros tiempos; Faye Greener, por su parte, guarda semejanza con la Prostituta de Babilonia, con su inevitable

9. Aunque soy reticente a plantear correlaciones entre la realidad y la ficción, sí llama la atención la similitud de esta actitud con el planteamiento vitalista de Nathanael West, lo que W.H. Auden definió como "West's Disease". Para el poeta inglés, West adolecía de la incapacidad de soñar porque cada vez que imaginaba un futuro esperanzador lo hacía derivar irremediablemente hacia lo grotesco: "This is a disease of consciousness which renders it incapable of converting wishes into desires. [...] All wishes, whatever their apparent content, have the same and unvarying meaning: 'I refuse to be what I am.' A wish, therefore, is either innocent and frivolous, a kind of play, or a serious expression of guilt and despair, a hatred of oneself and every being one holds responsible for oneself" (1962: 240-1). 
hechizo ante el que se someten todos los hombres ${ }^{10}$. A nivel temático, $D L$ reaviva los principales conceptos de la soteriología cristiana (tales como la redención, la liberación o la satisfacción) planteándose el dilema de la salvación o, más bien, la falta de ésta. Con respecto a la imaginería, la novela se llena de referencias al Apocalipsis, desde la coral de elegidos que piden la venida del Señor (p. 321), la lucha entre la serpiente y el hombre-ángel (p. 295), etc. El mito finalista bíblico, por tanto, se utiliza como modelo para enfatizar la conflictividad entre la historia humana y su deseo cultural de trascendencia, una de las características que Lois Zamora atribuye a la literatura apocalíptica moderna (1989: 12-3).

El sentido escatológico de $D L$, al contrario que la gran mayoría de la tradición apocalíptica norteamericana, no está supeditado a ningún factor externo. La obra está escrita en el período de transición entre las dos fases dominantes del apocalipticismo ficcional, una profundamente religiosa y otra secular pero externa, de modo que West pudo recrear una expectativa escatológica íntegramente humana. Antes del siglo XX, la práctica totalidad de las ficciones apocalípticas contenían un arraigado concepto milenarista que profetizaba la responsabilidad de Dios en la destrucción final; la ira de Dios, eje primordial en la ideología puritana, sería la única responsable de castigar al hombre con lo que el papel de éste se limitaría al de mero receptor de la justicia divina (May 1972: 26-9). A partir del siglo XX, especialmente en su segunda mitad, la ficción apocalíptica tiende hacia lo secular, sustituyendo la presencia divina por agentes externos (extraterrestres, meteoritos, desastres naturales, etc.) que tampoco permiten la participación directa del hombre en la conflagración final ${ }^{11}$. Frente a esa tipología, West concibe una debacle completamente humana, donde la inminencia del fin es fruto únicamente de las acciones realizadas por la sociedad californiana. Pese a la simbología neotestamentaria, no existen indicios de intervención divina o exterior en la obra: tanto la representación imaginada de la catástrofe final, el cuadro The Burning of Los Angeles, como la real, los disturbios populares frente al Khan's Persian Palace Theatre, son producto de una sociedad que se erige como única responsable de su destrucción.

10. Un extenso desarrollo de las dos primeras identificaciones puede encontrarse en Castro (2005: 112-5); la tercera pertenece a Lewis (1999: 440). Otras comparaciones entre $D L$ y el Apocalipsis podrían plantearse, como la de Earle Shoop y sus compañeros con los jinetes de Apocalipsis 12, pero estas equivalencias serían mucho más sutiles.

11. Para este tipo de literatura apocalíptica, usada especialmente en la ciencia-ficción, y sus subdivisiones, véase Ketterer (1974), Wagar (1982) o Dewey (1990). 
Esta humanización del pensamiento escatológico obliga a West a enfatizar sobre los aspectos sociales que conducen hacia esa catástrofe y, simultáneamente, derivan de ella. Sin un Dios-Juez supremo que castigue la actitud de sus personajes, el autor debe describirnos detalladamente el condicionamiento ético en que se desarrolla su novela y que, así, seamos los lectores los que concluyamos que ese mundo y esos seres verdaderamente "van a morir". Tod Hackett, recién llegado a la ciudad, será el encargado de ofrecernos un panorama completo del ethos californiano: a través de las acciones de unos pocos personajes, somos capaces de percibir una decadencia moral casi completa, donde la búsqueda de la diversión y el lujo se anteponen a cualquier valor social, y la violencia queda como una vía de escape de la frustración emocional. Prostitutas despreocupadas, enanos estafadores o vaqueros de postín forman la punta de lanza de un mundo que no responde a ningún argumento cívico.

Esa aparente falta de moralidad que describe Tod Hackett (la misma que parece molestar a parte de la crítica) y la dimensión apocalíptica que hemos resumido anteriormente tienen su punto de encuentro en la ética de interim. La sociedad retratada en $D L$, ante la pérdida de una expectativa de futuro, reacciona con la misma relativización moral que habíamos visto en las palabras de San Pablo. Un tiempo limitado implica un compromiso limitado y esa falta de compromiso es una de las características comunes de los protagonistas de la novela. Estos personajes han llegado a la conclusión de que no sirve de nada defender un sistema ético si no habrá un mañana donde desarrollarlo y, en consecuencia, pierden interés por todo fundamento moral: gozan del mundo como si no disfrutasen.

El mejor modo de ver el funcionamiento de la ética de interim en $D L$ es observar cómo Tod Hackett es arrastrado hacia ella según va integrándose en el mundo californiano. El joven artista, que llega a California para trabajar como pintor de decorados, se distingue del resto de los personajes en que él todavía posee una perspectiva de futuro, un plan vital para demostrar su valor:

Yet, despite his appearance, he was really a very complicated young man with a whole set of personalities, one inside the other like a nest of Chinese boxes. And 'The Burning of Los Angeles', a picture he was soon to paint, definitely proved he had talent. (p. 242)

Esa diferencia le permite disponer de uno de los últimos bastiones morales que aparentemente quedan en la novela: el amor. Su enamoramiento de Faye Greener representa una elección moral, contra corriente dentro del panorama de espectros sin afectividad que lo rodea. La misma Faye, sumida ya en la ética hollywoodiense de interim, es incapaz de amar y lo confiesa sin complejos: "she 
could only love a handsome man and would only let a wealthy man love her"(p. 250). El amor se ha convertido en un elemento prescindible dentro del Hollywood de West y Claude Estee, el guionista cínico que organiza veladas en los burdeles, sabe expresarlo perfectamente:

Love is like a vending machine, eh? Not bad. You insert a coin and press home the lever. There's some mechanical activity inside the bowels of the device. You receive a small sweet, frown at yourself in the dirty mirror, adjust your hat, take a firm grip on your umbrella and walk away, trying to look as though nothing had happened. It's good, but it's not for pictures. [...] I know. It's good, but it won't film. You've got to remember the audience. (pp. 255-6)

El desafío moral que plantea Tod al enamorarse de Faye choca frontalmente con la ética escatológica de ésta, que no amenaza con el rechazo, sino con la indiferencia, algo que resultaría mucho más doloroso: "He wanted to beg her for a kiss but was afraid, not because she would refuse but because she would insist on making it meaningless." (p. 293). Esa misma indiferencia, una minimización completa de las consecuencias éticas, es la que hace que Faye no dude en hacerse prostituta en el mismo funeral de su padre. En su decisión no hay ningún vestigio de planteamiento moral, simplemente se aborda el tema desde la asepsia de sentimientos. Sin embargo, también será esa actitud la que impida a Tod razonar con ella y convencerla de la inconveniencia de ese acto. Llegado el momento, Tod es incapaz de encontrar ningún razonamiento que pueda disuadir a Faye de su decisión porque lo hace apelando a sus inexistentes convicciones morales. $\mathrm{Su}$ actuación muestra lo absurdo del enfrentamiento entre un personaje que todavía considera ciertos valores éticos y otro engullido por una sociedad que no da relevancia a las implicaciones de cada acto:

He had to say something. She wouldn't understand the aesthetic argument and with what values could he back up the moral one? The economic didn't make sense either. Whoring certainly paid. [...] Suddenly he began to talk. He had found an argument. Disease would destroy her beauty. He shouted at her like a Y.M.C.A. lecturer on sex hygiene. (pp. 319-20)

La integración de Tod en la sociedad californiana, y con ello la adopción de su sistema de valores, conduce a la pérdida progresiva del sentimiento amoroso. El pintor sufre un proceso de entumecimiento emocional, que comienza con la despreocupación por lo que implica la nueva profesión de Faye (p. 330), sigue con el cinismo indiferente al saber que está viviendo con Homer Simpson (p. 332) y alcanza la máxima degradación al pedirle que se acueste con él por dinero (p. 341) o incluso pensar en la violación: "If only he had the courage to wait for her some night and hit her with a bottle and rape her." (p. 376). Ante este declive, Tod com- 
prende que ha sido absorbido por la desnaturalización de los valores éticos característica en sus vecinos, y se cuestiona su propio individualismo en oposición al resto de los personajes: "He began to wonder if he himself didn't suffer from the ingrained, morbid apathy he liked to draw in others. Maybe he could only be galvanized into sensibility and that was why he was chasing Faye." (p. 336).

El amor de Tod acaba siendo derrotado por la despreocupación emocional californiana, pero éste no es el único caso. Cualquiera de los núcleos vitales capaces de articular un sistema de valores es arrancado de raíz en $D L$. La muerte, que en cualquier sociedad estimula ciertos principios éticos (siempre se habla bien de los muertos) o, al menos, conmina al respeto, es trivializada del mismo modo. El funeral de Harry Greener (cap. 17) presenta una escena grotesca donde se regatea el precio del ataúd, el fallecido está pintado como un payaso e, incluso, su propia hija llora para los asistentes. La completa falta de sentimientos es la tónica general de los familiares y amigos, quienes deben ser forzados a presentar sus respetos al cadáver, alcanzando su grado máximo en la aparición de espectadores anónimos que han acudido con el único objetivo de librarse del aburrimiento:

He [Tod] knew their kind. While not torch-bearers themselves, they would run behind the fire and do a great deal of the shouting. They had come to see Harry buried, hoping for a dramatic incident of some sort, hoping at least for one of the mourners to be led weeping hysterically from the chapel. It seemed to Tod that they stared back at him with an expression of vicious, acrid boredom that trembled on the edge of violence. (pp. 320-1)

La insensibilidad de estos seres ante la muerte de Harry procede de una convivencia acostumbrada con la suya propia. Ninguno recibe el mensaje de memento mori que conlleva un funeral (así como la recuperación de ciertos valores espirituales), porque todos ellos son conscientes de antemano de su próximo fin. La muerte ajena no puede rivalizar con la sensación de muerte inminente que los personajes tienen en su interior, y de la que surge su peculiar sistema ético. El funeral, por tanto, pasa a ser un espectáculo sin profundidad emocional, otro divertimento más de la ociosa atmósfera hollywoodiense.

El mundo de la infancia, otro de los asideros tradicionales del fundamento ético, también es despojado de su peso en la obra. Es difícil encontrar una obra de ficción donde los niños no inspiren compasión a su alrededor, donde su inocencia no implique afectivamente. Sin embargo, el Hollywood que recrea West se asemeja a un matadero donde los niños son obligados por sus madres a demostrar un talento que sólo ellas ven, esperando hacer dinero a su costa: "Tod had seen her kind around the studio. She was one of that army of women who drag their 
children from casting office to casting office and sit for hours, weeks, months, waiting for a chance to show what Junior can do." (p. 333).

El caso de Adore Loomis, el hijo de la vecina de Homer Simpson, es notable. El carácter obsceno de la canción "Mama doan wan' no peas", que canta ante sus vecinos obligado por su madre (p. 335), nos provoca un rechazo visceral, producto de nuestras convicciones morales. Sin embargo, esta reacción no ocurre dentro de la novela: su audiencia, tal vez exceptuando a Tod, adolece de una insensibilidad demasiado ejercitada, que no alcanza a comprender la perversión del momento. La mezcla de sexo e infancia, que tanta polémica levantaría pocos años después en Estados Unidos con Lolita, no impresiona en la California apocalíptica imaginada por West.

Por lo tanto, se observa en la novela que los elementos que establecen la escala ética del ser humano, al ser enfrentados a la promesa escatológica, son minimizados y pierden toda su significación. No existen convicciones que exijan un compromiso o un esfuerzo, porque nada sobrevivirá a la catástrofe que se precipita sobre ellos. Cualquier tipo de credo, mediatizado por la cercanía del fin, se sostendrá en la relatividad moral: estamos, en definitiva, ante una versión moderna de la ética de interim. Los mismos fundamentos que predicaba San Pablo a las comunidades cristianas o que han defendido los principales movimientos apocalípticos a lo largo de la historia, articulan el discurso del predicador milenarista que Tod presencia cerca del final:

One Friday night in the "Tabernacle of the Third Coming", a man near Tod stood up to speak [...]. He was very angry. The message he had brought to the city was one that an illiterate anchorite might have given decadent Rome. It was a crazy jumble of dietary rules, economic and Biblical threats. He claimed to have seen the Tiger of Wrath stalking the walls of the citadel and the Jackal of Lust skulking in the shrubbery, and he connected these omens with "thirty dollars every Thursday and meat eating".

Tod didn't laugh at the man's rhetoric. He knew it was unimportant. What mattered were his messianic rage and the emotional response of his hearers. (pp. 337-8)

\section{Conclusiones}

Lo dicho anteriormente muestra que no podemos hablar de "inmoralidad" en $D L$ porque realmente no llega a establecerse ningún nivel moral según el cual pueda decirse quién está dentro de sus límites y quién no. El juicio ético no es posible si no está configurado un sistema teórico, necesario para poder 
juzgar ${ }^{12}$. Es imposible, en definitiva, que existan "cheaters", ya que no existe una definición clara de qué es "to cheat". Los personajes de $D L$ han dejado de preocuparse sobre lo que está bien y lo que está mal, conscientes de que esas categorizaciones son temporales y su tiempo es demasiado corto. Tampoco West, desde su perspectiva autorial superior, impone unos preceptos morales con los que poder impartir justicia a sus personajes. Los críticos que aseguran que West denuncia la decadencia y vileza de esa sociedad no encuentran testimonios textuales donde apoyar sus argumentos ${ }^{13}$ : cualquier juicio a la California representada provendrá de nuestros propios prejuicios como lectores no exentos de valores. Con los personajes salidos de su pluma, West tiene la misma actitud que con sus lectores: "I have no particular message for a troubled world (except possibly "beware") and the old standby of "pity and irony" seems like nothing but personal vanity" $"$.

Tampoco "amoralidad" es el término que define con exactitud la dimensión ética de $D L$, aunque el concepto sea mucho más aproximado. Los personajes de la novela no sólo poseen sus respectivos credos, sino que además asumen como una condición vital tenerlos. "Who do you follow? [...] I mean - in the search for Health, along the Road of Life?", pregunta Maybelle Loomis a Tod Hackett (p. 334). La necesidad de unos principios por los que regirse, de una guía para ese

12. Diciendo esto muestro mi desacuerdo con la teoría de John May (1972: 114-126) sobre el apocalipticismo basado en un "judgment of words and deeds" en la novelística de Nathanael West (lo explica con Miss Lonelyhearts, pero lo hace extensible a $D L$ ). Para May el logro de ciertos objetivos vitales tiene la propiedad de juzgar, algo que no tiene porqué ser así: si Miss Lonelyhearts o los personajes de $D L$ no consiguen sus sueños serán unos fracasados, pero eso no los convierte en personas malvadas. En mi opinión, el juicio procede más del propio May que de West.

13. Entre los estudiosos que opinan de este modo podemos mencionar a Comerchero (1964: 125), Cohen (1971: 48) o Veitch (1997: 124-9). Otros críticos, sin embargo, han destacado la pulcritud con que West evita interferir en la moral sus personajes como Alan Ross (1957: xi: "The Day of the Locust is his most mature work because in it his criticism of life is not intruding between the characters") o David Galloway (1971: 39-40: "in Miss Lonelyhearts and The Day of the Locust, West succeeds as an author because he is not attacking, but reflecting a side-tracked world of sorrow and despair, and because there satire is only a narrative device, and not his sole method").

14. Esta actitud, confesada por carta a su amigo, el también escritor Malcolm Cowley (May 11, 1939; p. 794), la resaltaron muchos de los críticos que conocieron a West directamente. Jay Martin, por ejemplo, decía: "West never attempted to correct society through satire or abandon it through irony; he held no dark mirror up to life. But he created a permanently true artistic vision, unaffected by alterations in the actual world. His works remain parallel to our lives, brilliant instruments through which we can measure and understand the crucial issues of our age. In them, West offered no comprehensive criticism of the temporal world; rather, he created a more permanent perspective by which that world, at any time, might be understood and judged." (1971: 10) 
"Road of Life", es una preocupación normal en el Hollywood moribundo de West. Todos abogan por la elección y participación en sus propias creencias morales, aunque éstas sean efímeras y banales. Faye Greener es consciente de la inutilidad de sus fantasías para el futuro y, aún así, opta por seguir soñando. Tod Hackett acaba comprendiendo que su cuadro apocalíptico será superado por la catástrofe real que se cierne sobre la ciudad, pero nunca renuncia a su creación. La actitud vital de los personajes es activa, todo el mundo tiene que seguir algo o a alguien, y nadie llega a abandonarse al nihilismo. El problema radica en que, debido a la proximidad del fin, sus elecciones se vuelven pueriles y sin sustancia: en vez de basarse en los valores que cualquier sociedad considera aceptables, los personajes de $D L$ recurren a dietas absurdas, fiestas artificiales o la visión lejana de una estrella de cine. Las preocupaciones normales del ser humano han perdido relevancia en este mundo.

Esta ética de interim no es más que es el resultado lógico de eliminar el segundo elemento del binomio causa-efecto, algo que sólo una concepción ficticia del tiempo permite. Frank Kermode, en su inspiradora The Sense of an Ending, diferencia entre el aevum (tiempo inmaterial, el equivalente al tiempo de las obras de ficción) y el saeculum (tiempo material y finito) basándose, entre otras cosas, en la posibilidad del primero de disociar los hechos de sus consecuencias:

[I]f an act could be without succession, without temporal consequence, one would welcome it out of a possible future into actuality; it would be like having hurly without burly. But acts without 'success' are a property of the aevum. Nothing in time can, in that sense be done, freed of consequence or equivocal aspects. (Kermode 1967: 86)

Los personajes de $D L$, presos de su seguridad apocalíptica, viven en una realidad donde sus actos no producen consecuencias. No habrá repercusiones, recompensas o castigos, salvo lo que pueda llegar tras la destrucción completa, por lo que cualquiera de sus acciones pierde gran parte de su gravedad. Sin juicio pendiente, olvidan la seriedad de sus decisiones vitales y las adaptan a su capricho momentáneo. Son, en definitiva, víctimas gozosas de esa "insoportable levedad del ser" que años más tarde describiera Milan Kundera desde la lejana Checoslovaquia.

Paradójicamente, podemos llegar a plantearnos si el final catastrófico que se cierne sobre esa California no será una bendición para sus habitantes. Al igual que el Apocalipsis bíblico combina los horrores de la destrucción con el optimismo esperanzador por la llegada del Reino de Dios, el cataclismo hollywoodiense supondrá el fin de la ética de interim que aletarga a los californianos:

Their boredom becomes more and more terrible. They realize that they've been tricked and burn with resentment. Every day of their lives they read newspapers and 
went to the movies. Both fed them on lynchings, murders, sex crimes, explosions, wrecks, love nests, fires, miracles, revolutions, wars. This daily diet made sophisticates of them. The sun is a joke. Oranges can't titillate their jaded palates. (p. 381)

La súplica contenida en la coral de Bach, "Now come, O our Saviour" (p. 322), es tan real como el deseo de la Segunda Venida de Cristo en la Iglesia primitiva. Sólo mediante el fuego purificador del cuadro de Tod se podrá aliviar el aburrimiento insensibilizador de los personajes. La última, terrible, reflexión de West en The Day of the Locust parece cuestionar qué tipo de sociedad es más fácilmente admisible: la deshumanizada completamente o la destruida en su totalidad.

\section{BIBLIOGRAFÍA}

Alter, Robert: "The Apocalyptic Temper". Commentary 41 (1966). 61-66.

Auden, W.H.: "West's Disease". The Dyer's Hand and Other Essays. New York: Random House, 1962. 238-45.

Bercovitch, Sacvan, ed.: Nathanael West. Novels and Other Writings. New York: The Library of America, 1997.

Britton, Florence Haxton: "New Novels from Far and Near". The New York Herald Tribune Books (21 May 1939). 7.

Castro Carracedo, Juan Manuel: "The Day of the Locust de Nathanael West frente al concepto apocalíptico americano". Estudios de literatura en lengua inglesa de los siglos XX y XXI (8). Eds. José Manuel Barrio y Pilar Abad. Valladolid: Universidad de Valladolid, 2005. 107-121.

Cohen, Arthur: "The Possibility of Belief: Nathanael West's Holy Fool". Twentieth Century Interpretations of Miss Lonelyhearts. Ed. Thomas H. Jackson. Englewood Cliffs, N.J.: Prentice Hall, 1971. 46-8.

Comerchero, Victor: Nathanael West. The Ironic Prophet. Syracuse: Syracuse University Press, 1964.

Dewey, Joseph: In a Dark Time: The Apocalyptic Temper in the American Novel of the Nuclear Age. West Lafayette, Indiana: Purdue University Press, 1990.

Díaz Rodelas, Juan M.: Primera Carta a los Corintios. Estella: Verbo Divino, 2003. Galloway, David D.: "A Picaresque Apprenticeship: Nathanael West's The Dream Life of Balso Snell and A Cool Million". Nathanael West: A Collection of Critical Essays. Ed. Jay Martin. Englewood Cliffs, N.J.: Prentice Hall, 1971. 31-47.

Harkness, Georgia: Understanding the Kingdom of God. New York: Abingdon Press, 1974.

Hyman, Stanley Edgar: Nathanael West. University of Minnesota Pamphlets on American Writers 21. Minneapolis: University Of Minnesota Press, 1962. 
Jones, Margaret Catherine: Prophets in Babylon: Four California Novelists in the 1930s (Steinbeck, Huxley, West, Armstrong). Ph.D. Dissertation, Purdue University. Ann Arbor: UMI Dissertation Services, 1989.

Kermode, Frank: The Sense of an Ending: Studies in the Theory of Fiction. London: Oxford University Press, 1967.

Ketterer, David: New Worlds for Old: The Apocalyptic Imagination, Science Fiction, and American Literature. Garden City, N.Y.: Anchor Books, 1974.

Knox, John: Jesus Lord and Christ. New York: Harper \& Brothers, 1958.

Lewis, Kevin: "Nathanael West and American Apocalyptic." Tradition and Postmodernity: English and American Studies and the Challenge of the Future. Eds. Teresa Bela and Zygmunt Mazur. Krakow, Poland: Jagiellonian University, 1999. 435-43.

Martin, Jay: "Introduction". Nathanael West: A Collection of Critical Essays. Ed. Jay Martin. Englewood Cliffs, N.J.: Prentice Hall, 1971. 1-10.

May, John R.: Toward a New Earth: Apocalypse in the American Novel. Notre Dame, Indiana: University of Notre Dame Press, 1972.

Ross, Alan, ed.: The Complete Works of Nathanael West. New York: Farrar, Straus and Cudahy, 1957.

Schwartz, Musia Miriam: Prophets for a Cold Age: Isaac Babel and Nathanael West. Ph.D. Dissertation, McGill University. Ann Arbor: UMI Dissertation Services, 1980.

Schweitzer, Albert: The Quest of the Historical Jesus. A Critical Study of its Progress from Reimarus to Wrede. London: A\&C Black, 1910.

Sheehan, Thomas: How the Kingdom of God Became Christianity. New York: Random House, 1986.

Springer, John: “"This is a riot you're in': Hollywood and American Mass Culture in Nathanael West's The Day of the Locust". Literature Film Quarterly 24 (1996). 439-45.

Veitch, Jonathan: American Superrealism: Nathanael West and the Politics of Representation in the 1930s. Madison: University of Wisconsin Press, 1997.

Wagar, W. Warren: Terminal Visions. The Literature of the Last Things. Bloomington: Indiana University Press, 1982.

Young, Gloria: "The Day of the Locust: An Apocalyptic Vision”. Critical Essays on Nathanael West. Ed. Ben Siegel. New York: GK Hall, 1994. 177-83.

Zamora, Lois Parkinson: Writing the Apocalypse. Historical Vision in Contemporary U.S. and Latin American Fiction. Cambridge: Cambridge University Press, 1989.

Zimbaro, Valerie P.: Encyclopedia of Apocalyptic Literature. Santa Barbara, CA.: ABC-Clio, 1996. 